\title{
Nesting information for Tropeiro Seedeater (Sporophila beltoni), an endemic songbird from southern Brazil
}

\author{
Márcio Repenning ${ }^{1,2} \&$ Carla Suertegaray Fontana ${ }^{1}$ \\ 1 Laboratório de Ornitologia, Museu de Ciências e Tecnologia, Curso de Pós-graduação em Ecologia e Evolução da Biodiversidade, Pontifícia \\ Universidade Católica do Rio Grande do Sul - PUCRS, Porto Alegre, RS, Brazil. \\ 2 Corresponding author: mrepenning@gmail.com
}

Received on 12 September 2018. Accepted on 02 September 2019.

\begin{abstract}
We present the first nesting information for the Tropeiro Seedeater (Sporophila beltoni), a newly described and poorly known Neotropical passerine endemic to southern Brazil. We observed a novel male biased behavior for nest site selection in the Tropeiro Seedeater based on seven events of pre-nesting display courtship. We describe the nest, eggs, nestlings, and fledglings based on 133 nests found over four breeding seasons (2007 to 2011). The nest is a cup-shaped structure made with dry grass inflorescences and spider webs. It is placed in low, forked branches of substrate shrubs and contains multiple attachment points. The eggs are typically white with dark spots or stripes, and are pyriform in shape. Average egg dimensions are $18.2 \times 13.2 \mathrm{~mm}$. Nestlings fledge after 10 days. We provide the key information for distinguishing the nest, eggs, nestlings and fledglings of $S$. beltoni from other sympatric Sporophila species.
\end{abstract}

KEY-WORDS: austral migrant, breeding biology, fledgling description, nest site selection, nestlings.

\section{INTRODUCTION}

The Tropeiro Seedeater, Sporophila beltoni, is the rarest and perhaps the most threatened of the 35 species of Neotropical seedeaters. It breeds in a limited zone from upland shrub-grasslands of southern Brazil and migrates north to its wintering grounds in the Cerrado Biome. This species was recently split from the Plumbeous Seedeater (Sporophila plumbea) which occurs in Cerrado savanna (Repenning \& Fontana 2013). Its distinguishing features are the bluish-gray plumage and bright-yellow bill in males. The Tropeiro Seedeater has a restricted and fragmented distribution, and has experienced population declines due to habitat loss and pressure from bird trappers (Repenning et al. 2010). The species is classified as "Vulnerable" globally (BirdLife International 2017).

Information about nesting biology of Sporophila species has been increasing, now including details about several species such as S. caerulescens (Francisco 2006), S. hypoxantha (Facchinetti et al. 2008, Bichinski 2011, Franz \& Fontana 2013), S. cf. hypochroma (Roda \& López-Lanús 2008), S. collaris (Facchinetti et al. 2008), S. leucoptera (Francisco 2009), S. melanogaster (Rovedder \& Fontana 2012, Fontana \& Repenning 2014) and S. lineola (Oliveira et al. 2010). These information may provide the basis for comparative analyses of nesting behavior and provide the necessary background to assess the evolutionary relationships within the Sporophila genus.

Basic information such as description of nests, eggs and nestlings are prevalent in studies about reproductive biology of the group. The behavior involving parental care and, to a lesser extent, estimates of survival and reproductive success have also been determined (Facchinetti et al. 2008, Franz \& Fontana 2013, Repenning \& Fontana 2016). However, one poorly known aspect concerning the Sporophila genus is its premating behavior and the role of males and females in the selection of the nest site (Rising et al. 2012). Here, we studied the breeding biology of the Tropeiro Seedeater for 4 years and present the first description of its pre-nesting behavior, nest, eggs and nestlings/fledglings.

\section{METHODS}

We carried out the study in the southern Brazilian uplandgrasslands of south Santa Catarina and northeastern Rio Grande do Sul states $\left(28^{\circ} 26^{\prime} \mathrm{S} ; 50^{\circ} 24^{\prime} \mathrm{W}\right)$, during 4 breeding seasons (from October to March, 2007- 
2011). The study areas comprise valley shrub-grasslands on very steep terrain, at elevations from 700 to $950 \mathrm{~m}$ a.s.l. (Repenning et al. 2010). We followed adult birds as soon as they arrived in the breeding areas beginning in late October. We then searched for nests by observing breeding evidences of paired birds. We evaluated nest building by focal observation with a telescope $(20 \times 60$ $\mathrm{mm})$, or made video recordings. We video-recorded 14 nests during nest building $(34 \mathrm{~h})$. We measured the nests and support plants with an analog caliper $(0.01 \mathrm{~mm})$ and a ruler $(0.5 \mathrm{~mm})$. We collected the plants used as nest support and as nest materials for identification of species. Scientific botanical names follow The Plant List (2013).

We weighed the eggs when they were reasonably freshly-laid (i.e., 1-3 days from lay). We weighed nestlings $(n=74)$ daily with a digital balance $(0.01 \mathrm{~g})$, and measured eggs with caliper $(0.01 \mathrm{~mm})$. We determined the relative mass of eggs by dividing mean egg mass by mean female body mass. For monitoring nestlings/fledglings we banded them using aluminum bands provided by the Brazilian Banding Agency (CEMAVE/ICMBio) and with a combination of color bands. We used the Smith's (1975) color catalog to standardize the description of the color of eggs and nestlings.

\section{RESULTS}

\section{Selection of the nest site}

We observed males performing a secretive and peculiar display courtship during nest site choice by females. Nest sites were located in a particular habitat type, in general a patch of shrubs among rocks in dry soils in steep places. In seven independent cases observed, the males performed a typical short flight within a bush, calling very specific song notes and exposing the white wing speculum (i.e., vibrating wings like an on/off signal) while they were followed by the female. Each male visited suitable forks in the shrubs making movements similar to those executed by females when shaping the chamber of the nest. Soon after that the female follows the male and check each bush, testing the places indicated by male with a brooding posture. In all the times observed the females allocated their nests in the fork of bush visited/indicated by male and tested previously. Each event observed included multiple male suggestions of potential nesting places within the breeding territory, however the nest attempts were always in the same patches of bushes each annual cycle. We recorded about 30 males that returned to the same breeding territory that changed their nesting sites by only a few meters in successive years, most of them within the same vegetation patch. Nesting attempts were usually with different females across breeding seasons. Six reproductive males observed performing nest site display were males with final plumage and only one had a formative drab plumage (first year) male.

\section{Nest building and nest materials}

The nest is a low cup (sensu Simon \& Pacheco 2005), located in a fork of a bush (sensu Simon \& Pacheco 2005), made with dry grass inflorescences and attached with spider webs to the substrate through multiple points (sensu Hansell 2000). Construction of the nest takes 5 days on average (range 4-10 days, $n=15$ nests) and is only performed by the female (Fig. 1). We identified 16 species of shrubs used for nesting in the following families: Asteraceae (12), Myrtaceae (2), Escalloniaceae (1) and Anacardiaceae (1) (Fig. 1). Fibers used to build nests were inflorescences from the genera Eragrostis and Panicum. Eragrostis airoides and E. polytricha were also present in all nest linings of the incubation chambers of nests. Inflorescences such as Calamagrostis viridiflavescens, Briza spp., Paspalum spp., Eustachys uliginosa, and lichen (Usnea sulcata) appeared in low frequency in the composition of the nests, and were used in the outer edge of some nests only. Fibers were tied up with spider webs. We recorded three events of females collecting webs from ground funnel webs of the spider Aglaoctenus lagotis (Lycosidae) (Fig. 1). We summarize the morphometric parameters of the nests in Table 1.

\section{Eggs and nestlings}

The eggs typically have a whitish background, ranging from pale cream tones (Pale Cream Horn) to shades of turquoise (Turquoise Green; Smith 1975). The spots or strips are grayish, black, beige, brown or burgundy, and may be of an intense shade or pale. The shape of the eggs ranged from pyriform (predominant) to oval (Fig. 1). The mean morphometric parameters of eggs were: length = $18.2 \pm 0.14 \mathrm{~mm}$ (range 17.2-19.3 $\mathrm{mm}, n=26$ ); width $=$ $13.2 \pm 0.08 \mathrm{~mm}$ (range 12.7-14.1 mm, $n=26$ eggs) and mass $1.46 \mathrm{~g} \pm 0.03 \mathrm{~g}$ (range $1.29-1.64 \mathrm{~g}, n=16 \mathrm{eggs}$ ). The relative mass of eggs was on average $12.2 \%$ of the female body mass.

Newly hatched nestlings had a body mass average of $1.29 \mathrm{~g}$ and when they left the nest they had a body mass average of $9.03 \mathrm{~g}$ (Fig. 2). In the first two days the nestlings were quiet and have thin, transparent, pinkish skin with tufts of grayish-white down sparsely covering the head, back, wings and flanks. The bill tip is yellowish with yellowish commissure, and a pinkish-orange lining of the mouth. At day 2 the pins of remiges become visible. Nestlings' eyes open on day 4, when the remiges (pin feathers) and contour feathers start to emerge. The growth of body neossoptiles occurs in the following order: coronal/occipital, dorsal, pelvic and femoral. The feathers sheaths disintegrate on days 6 to 8 , ending the pin feather 

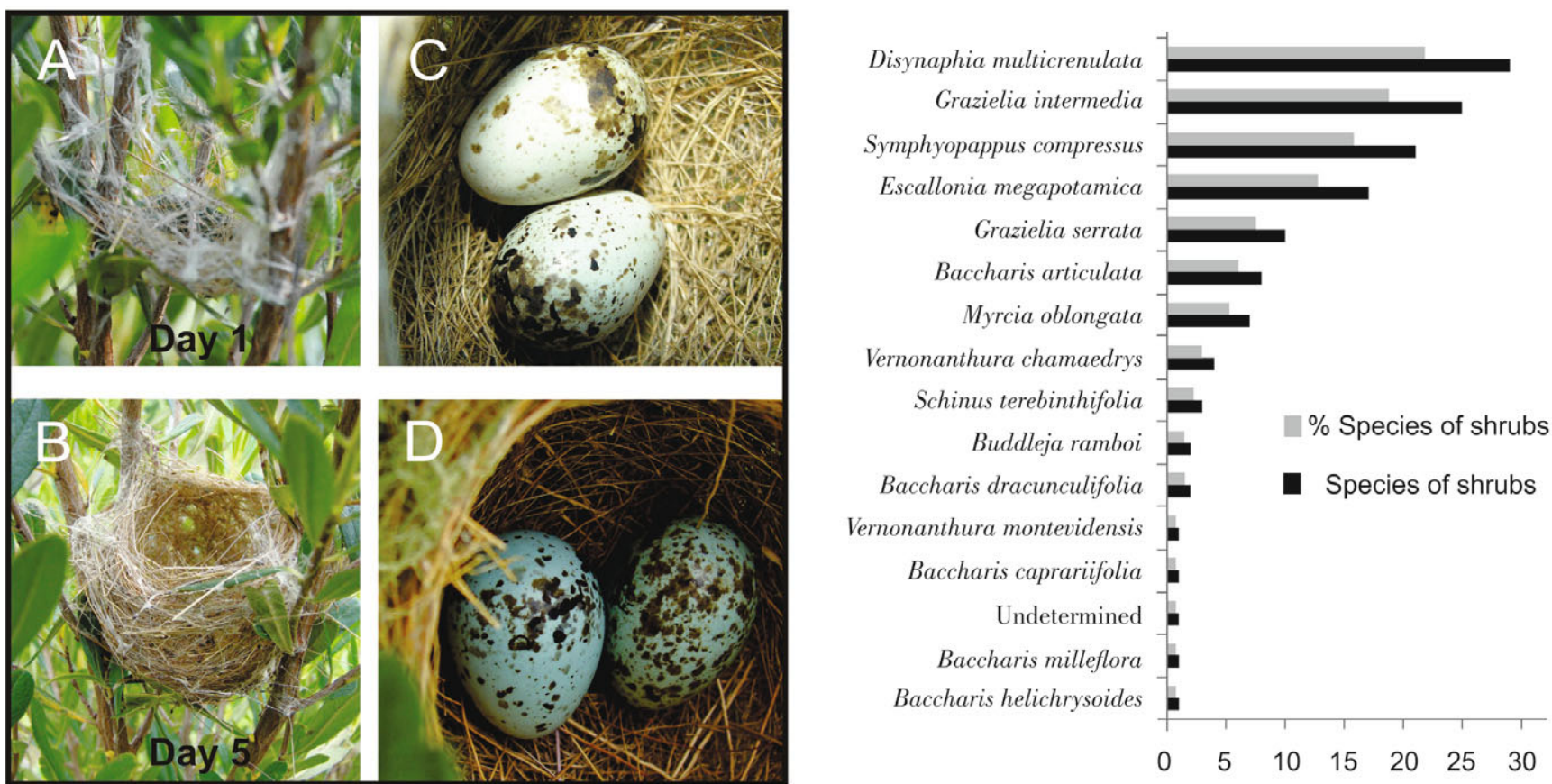

Figure 1. Nest of Tropeiro Seedeater Sporophila beltoni in the initial (A) and final phases (B) of construction (days 1 and 5, respectively). Eggs showing variation in background color, white/pale $(\mathbf{C})$ and turquoise $(\mathbf{D})$ and spotting patterns. On the right is a list of species of shrubs that were used as substrates for nests of the Tropeiro Seedeater ( $n=133$ nests).

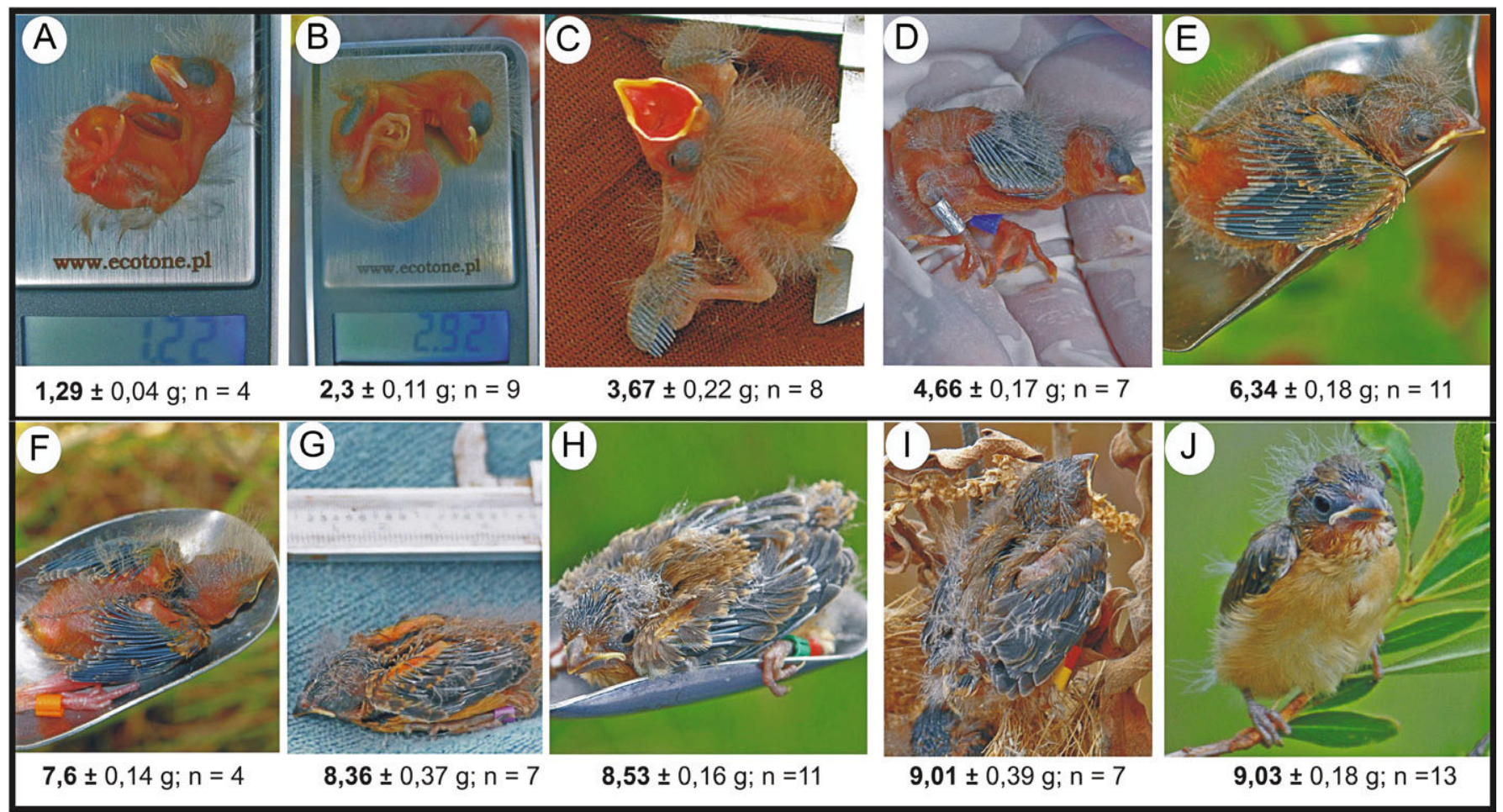

Figure 2. Daily growth (mean \pm SE body mass) of nestlings and fledglings of the Tropeiro Seedeater, Sporophila beltoni.

stage. Around day 10 the nestlings' plumages are poorly complete and with short tails when they leave the nests (Fig. 2). Between 10 and 13 days fledglings have limited flight. The general color of covert feathers and remiges are a drab brown and the culmen is Sepia/Brown. Feeding independence of fledglings occurs around day 50 when they exhibit the complete juvenile plumage or starting the pre-formative molting.

\section{DISCUSSION}

\section{Selection of the nest site}

We revealed a novel behavior that involves the selection of nest sites in the Tropeiro Seedeater. The repeated pre-nesting male behavior suggests a strong male bias in indicating the site for nest-building to the female, 
although the male abstains completely from the nest building phase. This breeding behavior has not been described for any other species of Neotropical seedeater, or for other passerines in the region. In monogamous species the selection of the nest site often results from a subtle interplay between the two sexes where male and female inspect potential nest sites together (Collias \& Collias 1984). Analogous behavior has been documented for Australian grass-finches (Estrildidae), in which the male leads his mate and indicates the potential nest places. After finding a suitable fork of a branch he attracts the female's attention to it by hopping back and forth, uttering special calls. However, the final choice is then made by the female (Immelmann 1965). Far beyond philopatry the results presented here shows fidelity of specific places for nesting within the same territories each season. Oldest males were tenacious to same breeding territories which contributes for stability on nest site year after year. Hence, we emphasize that nesting success from previous breeding season(s) may be the ultimate factor shaping this rare pre-nesting behavior (Payne 1979, Repenning \& Fontana 2016).

\section{Nest, eggs and nestlings}

The nest of $S$. beltoni is similar to that of another syntopic Sporophila species. However, our results provide sufficient details for reliable diagnosis when compared to congeners' nests. In contrast to nests of $S$. caerulescens (Francisco 2006), the nest of $S$. beltoni is slightly larger (deeper, with inner diameter largest and thicker edge). Also, S. beltoni do not nest in trees and do not use herbal root fibers in the incubation chamber, which are common features for S. caerulescens nests. Sporophila beltoni nests have greater inner diameter and depth, on average, compared with nests of other Capuchino species (e.g., S. melanogaster, $S$. hypoxantha and $S$. pileata) and nests are always placed at greater heights. The adhesion of the nest to the substrate in S. beltoni differ from other Capuchino species which can be classified as bottom multiple vertical (sensu Simon $\&$ Pacheco 2005). Additionally, the wall of S. beltoni nests is thinner and less dense than that of nests of sympatric Capuchinos' species. Sporophila beltoni do not nest on clumps of grasses while Capuchinos nesting on clumps of grasses or on mixed clumps and sub-bushes has been described (Bichinski 2011, Rovedder \& Fontana 2012, Franz \& Fontana 2013).

The color pattern of the eggs of $S$. beltoni varies, and they appears almost indistinguishable from eggs of other Sporophila spp. based on color and shape. However, the species has some of the largest eggs among the Sporophila for which dimensional size data are available. They are, on average, smaller only than eggs of $S$. leucoptera and are equivalent to the size of those of the allopatric $S$. collaris (disregarding Oryzoborus). The relative mass of the eggs is within the range of the values reported for other congeners. However, the relative mass of the eggs is substantially greater than has been determined for other temperate-zone passerines ( 4.5 to $7.7 \%$ of the female body mass) (Welty \& Baptista 1988).

Juveniles of Sporophila can be cryptic in areas where two or more sympatric species occurs. Sporophila beltoni juveniles are similar to those of $S$. hypoxantha, S. melanogaster and $S$. pileata, but have larger body size (length and mass) and lack the tawny/buff colored plumage usually present in Capuchino juveniles. When the first pre-formative molt starts in $S$. beltoni they then show no white wing speculum, which is present in Capuchinos. The nestling/fledgling of $S$. caerulescens, might overlap in measurements and plumage color with $S$. beltoni nestling/ fledgling. However, while they complete the pre-juvenal molt $S$. beltoni retains the brown plumage while $S$. caerulescens acquires an olive drab plumage (M.R. unpub. data). Finally, we suggest that the description of Tropeiro Seedeater associated to illustration in details of the nestlings until they fledge can provide useful parameters for estimating the nestling's age in other breeding biology studies of Neotropical seedeaters.

\section{ACKNOWLEDGEMENTS}

We thank M.L. Gonçalves, I. Franz, and C.E. Rovedder for fieldwork assistance; Ilsi I. Boldrini and her team from Laboratory of Botany of UFRGS for botanical identification. We also would like to thank Dra. Regina H. Macedo and E. Chiarani for text review; Fundação Grupo Boticário de Proteção à Natureza (FBPN-project No. 0795-20082), Neotropical Grassland Conservancy, and IGRÉ - Associação Sócio Ambientalista for financial support. Brazilian Federal Agency (CAPES) and National Research Council (CNPq) for scholarship to M.R. and funding to C.S.F.; CEMAVE/ICMBio for bands; Federal agency SISBIO for permission to project No. 13310.

\section{REFERENCES}

Bichinski T.A. 2011. Comportamento reprodutivo de Sporophila hypoxantha (Passeriformes: Emberizidae) no estado do Paraná. Atualidades Ornitológicas 163: 57-61.

BirdLife International 2017. Species factsheet: Sporophila beltoni. http://www.birdlife.org (Access on 26 September 2017).

Facchinetti C., Di Giacomo A. \& Reboreda J.C. 2008. Parental care in Tawny-bellied (Sporophila hypoxantha) and Rusty-collared ( $S$. collaris) Seedeaters. Wilson Journal of Ornithology 120: 879-883.

Fontana C.S. \& Repenning M. 2014. Black-bellied Seedeater (Sporophila melanogaster). In: Schulemberg T.S. (ed.). Neotropical birds online. Ithaca: Cornell Lab of Ornithology. http:// neotropical.birds.cornell.edu/portal/species/overview?p_p_ spp $=627596$ 
Francisco M.R. 2006. Breeding biology of the Double-collared Seedeater (Sporophila caerulescens). Wilson Journal of Ornithology 118: 85-90.

Franz I. \& Fontana C.S. 2013. Breeding biology of the Tawny-bellied Seedeater (Sporophila hypoxantha) in south Brazilian upland and grasslands. Wilson Journal of Ornithology 125: 280-292.

Hansell M. 2000. Bird nest and construction behavior. Cambridge: Cambridge University Press.

Ralph C.J., Geupel G.R., Pyle P., Martin T.E., De Sante D.F. \& Milá B. 1996. Manual de métodos de campo para el monitoreo de aves terrestres. Albany: Department of Agriculture.

Repenning M., Rovedder C.E. \& Fontana C.S. 2010. Distribuição e biologia de aves nos campos de altitude do sul do Planalto Meridional Brasileiro. Revista Brasileira de Ornitologia 18: 283306.

Repenning M. \& Fontana C.S. 2013. A new species of Gray Seedeater (Emberizidae: Sporophila) from upland grassland of southern Brazil. Auk 130: 791-803.

Repenning M. \& Fontana C.S. 2016. Breeding biology of the Tropeiro Seedeater (Sporophila beltoni). Auk 133: 484-496.

Rising J., Jaramillo A., Copete J.L., Madge S. \& Ryan P. 2011. Family
Emberizidae (buntings and New World sparrows), p. 492-709 In: del Hoyo J., Elliott A. \& Christie D.A. (eds.). Handbook of the birds of the world, v. 16 (tanagers to New World blackbirds). Barcelona: Lynx Editions.

Roda M.Á. \& López-Lanús B. 2008. The range of Rufous-rumped Seedeater Sporophila hypochroma extends to the Pampas region of Argentina, with the first nest of the species. Cotinga 30: 61-62.

Rovedder C.E. \& Fontana C.S. 2012. Nest, nest placement, and eggs of Black-bellied Seedeater (Sporophila melanogaster) an endemic bird of Brazil. Wilson Journal of Ornithology 124: 173-176.

Simon J.E. \& Pacheco S. 2005. On the standardization of nest descriptions of Neotropical birds. Revista Brasileira de Ornitologia 13: $143-154$.

Smith F.B. 1975. Naturalist's color guide. New York: The American Museum of Natural History.

The Plant List 2013. A working list of all plant species. http://www. theplantlist.org (Access on 06 September 2019).

Welty J.C. \& Baptista L. 1988. The life of birds. New York: W.B. Sauders.

Associate Editor: Caio G. Machado. 